\title{
La Separación de Hecho de los Cónyuges como causa de la Separación de Cuerpos y del Divorcio: Peculiaridades
}

\section{Common law separation of spouses as a cause of physical separation and divorce: specific traits}

\section{Resumen}

\section{María Teresa Cornejo Fava*}

El principio constitucional de protección de la familia y de promoción del matrimonio por la comunidad y por el Estado y de su reconocimiento como institutos naturales $y$ fundamentales de la sociedad. Contradicción de la legislación civil con el principio constitucional antes enunciado.

\section{Palabras clave}

Promoción del matrimonio. Matrimonio: instituto natural y fundamental de la sociedad. Contradicción entre legislación civil y principio constitucional. Separación de hecho, causa de separación de cuerpos y de divorcio. Inaplicación de la teoría del hecho propio. Requisito previo. Estabilidad económica. Cónyuge más perjudicado.

\begin{abstract}
This article addresses the constitutional principles of protecting families and promoting marriage by the community and the State and their recognition as natural and fundamental institutions of society, while discussing the contradiction of civil law with such constitutional principles.
\end{abstract}

\section{Key words}

Promotion of marriage. Marriage: natural and fundamental institutions of society. Contradiction between civil law and constitutional principles. Common law separating, cause of physical separation and divorce. Exception to the venire contra factum proprium non valet principle. Prerequisite. Economic stability. Injured spouse.

\footnotetext{
* Abogada. Bachiller en Derecho y Abogada por la Pontificia Universidad Católica del Perá. Con estudios de Maestría en Derecho Civil y Comercial (2003 - 2004) y de Doctorado de Derecho y Ciencia Política (2005 - 2006) en la Escuela de Postgrado de la Universidad Nacional Mayor de San Marcos. Experiencia en el ejercicio de la profesión y en la Docencia Universitaria en temas de Derecho de Familia - Derecho de Sucesiones - Legislación de Hidrocarburos. Integrante de Comisiones de Revisión y de Elaboración de normas vinculadas con el derecho de familia y con los derechos de niños y adolescentes.
}

Fecha de recepción: 25/07/2014

Fecha de aceptación: 20/08/2014 


\section{Introducción}

La Constitución consagra la protección de la familia y la promoción del matrimonio por la comunidad y por el Estado, reconociendo a ambos como institutos naturales y fundamentales de la sociedad.

El principio constitucional de protección de la familia, de promoción del matrimonio por la comunidad y por el Estado, y del reconocimiento de ambos como institutos naturales y fundamentales de la sociedad, se refleja en la enumeración taxativa de las causas de separación de cuerpos y divorcio ulterior, en la prohibición de invocar el hecho propio a efectos de determinar una de ellas como fundamento de la pretensión dirigida a este fin y en la admisión de la separación de cuerpos convencional únicamente dos años después de la celebración del matrimonio.

Tres hechos de "reciente" data evidencian una contradicción con el principio constitucional antes enunciado: [a] la admisión de nuevas causas para la separación de cuerpos y para el divorcio; [b] la inaplicación de la teoría de los hechos propios en la causa de separación de hecho invocada como sustento de la separación de cuerpos y divorcio ulterior; y, [c] el requisito previo exigido para la invocación de esta causa con el propósito ya indicado.

\section{Principio Constitucional de Protección de la Familia y de Promoción del Patrimonio}

En su artículo $4^{\circ}$, la Constitución de 1993 consagra los principios de protección especial del niño, del adolescente, de la madre y del anciano en situación de abandono, por la comunidad y por el Estado; de protección de la familia; de promoción del matrimonio; y del reconocimiento de familia y matrimonio como institutos naturales y fundamentales de la sociedad.

\section{Reflejo de este Principio Constitucional}

El principio constitucional de protección de la familia y de promoción del matrimonio por la comunidad y por el Estado y de su reconocimiento como institutos naturales y fundamentales de la sociedad se refleja en la enumeración taxativa de las causas de separación de cuerpos y divorcio ulterior; en la prohibición de invocar el hecho propio a efectos de determinar una de ellas como fundamento de la pretensión dirigida a este fin; y en la admisión de la separación de cuerpos convencional únicamente dos años después de la celebración del matrimonio. 


\section{Contradicción con el Principio Constitucional ya Enunciado}

No obstante, tres hechos de "reciente" data evidencian una contradicción con el principio constitucional antes enunciado: [a] la admisión de nuevas causas; [b] la inaplicación de la teoría de los hechos propios en la causa de separación de hecho invocada como sustento de la separación de cuerpos y divorcio ulterior; $\mathrm{y},[\mathrm{c}]$ el requisito previo para su invocación como fundamento de la separación de cuerpos y del divorcio ulterior.

\section{Determinación, numerus clausus, de causas para la obtención de la Separación de Cuerpos y/o Divorcio}

Desde la admisión de la disolución del vínculo matrimonial por causas previas y ajenas a la muerte de uno de los cónyuges -producida en 1930 y recogida por vez primera en el Código Civil de 1936- la normativa civil en la materia ha consagrado un régimen taxativo, numerus clausus, relativo a las causas susceptibles de invocación a efectos de la obtención de la separación decuerpos y/o divorcio.

Ello se advierte claramente del Código Civil antes citado cuyo artículo $297^{\circ}$ recogió nueve causas a ser invocadas por el cónyuge que pretendiera obtener la disolución de su vínculo matrimonial.

Su artículo $249^{\circ}$ dispuso que "ninguno de los cónyuges puede fundar la acción de divorcio en hecho propio": se trata de causas sustentadas en la conducta no del cónyuge que pretende tal disolución sino en la conducta del "otro" cónyuge, esto es del cónyuge demandado.

Continuando con esta línea de acción, el Código Civil vigente consagró, en el texto primigenio de su artículo $333^{\circ}$, diez causas susceptibles de invocarse con el propósito de obtener la separación de cuerpos y/o el divorcio.

Asimismo, en su artículo $335^{\circ}$ este Código recoge el enunciado según el cual ninguno de los cónyuges puede fundar en hecho propio la demanda [de separación de cuerpos y/o de divorcio].

La Carta de 1979 es el primer texto constitucional que se ocupa de la familia y del matrimonio, declarando en su artículo $5^{\circ}$ la protección, por el Estado, del matrimonio y la familia como sociedad natural e institución fundamental dela Nación.

En la misma línea, el artículo $4^{\circ}$ de la Constitución de 1993 consagra los principios de protección de la familia, de promoción del matrimonio, y de 
reconocimiento de familia y matrimonio como institutos naturales $y$ fundamentales de la sociedad.

Interesa señalar que, en este orden de ideas, no se trata únicamente de proteger estas instituciones.

Se trata de la promoción del matrimonio, instituto natural y fundamental de la sociedad, por la comunidad y por el Estado, no meramente de su protección.

La "promoción" de este instituto de la sociedad implica una actitud dirigida no únicamente a incentivar su celebración sino, de modo especial, a velar por su permanencia durante la existencia de los cónyuges de modo que sea el fin de ella la que ponga fin al matrimonio.

Esta situación ideal se ve reflejada en la norma del artículo $360^{\circ}$ del Código Civil vigente en virtud de cuyo enunciado las disposiciones de la ley sobre el divorcio y la separación de cuerpos no se extienden más allá de sus efectos civiles y dejan íntegros los deberes que la religión impone.

Constituye antecedente de esta disposición el artículo $292^{\circ}$ del Código Civil de 1936 cuyo tenor establece que, en lo concerniente al matrimonio, las disposiciones de la ley no se extienden más allá de sus efectos civiles, dejando integros los deberes que la religión impone.

En este orden de ideas y en armonía con los principios enunciados, constituye consecuencia lógica de este principio constitucional que el ordenamiento civil contribuya a la promoción del matrimonio tanto en cuanto se refiere a su celebración como a su permanencia a lo largo de la vida de varón. y mujer unidos por este vínculo.

Manifestación necesaria de ello es que la legislación en la materia conserva el régimen taxativo, numerus clausus, relativo a las causas a ser invocadas como sustento de una pretensión dirigida a la obtención de la separación de cuerpos y/o divorcio, y a las exigencias para la acreditación de las mismas.

\section{Ampliación de causas para la obtención de la Separación de Cuerpos y/o Divorcio}

No obstante, la normativa civil ha ampliado, a la fecha, a doce el número de causas que constituyen situaciones susceptibles de ser invocadas a modo de sustento de la pretensión orientada a la obtención de la separación de cuerpos y/o del divorcio. 


\section{La Separación de hecho de los Cónyuges: Causa de la Separación de Cuerpos y/o del Divorcio}

En el año 2001, el artículo $2^{\circ}$ de la Ley $N^{\circ} 27495$ consagró como numeral 12 del artículo $333^{\circ}$ del Código Civil como causa de separación de cuerpos y/o del divorcio la "separación de hecho de los cónyuges durante un período ininterrumpido de dos años", plazo que será de cuatro años si los cónyuges tuviesen hijos menores de edad.

En su parte final el numeral 12 de este artículo $333^{\circ}$ dispone de modo expreso que, en este caso "... no será de aplicación lo dispuesto en el artículo $335^{\circ \prime \prime}$,

Así pues, a diferencia de las demás hipótesis causales que pueden sustentar una acción de esta naturaleza, al demandar la separación de cuerpos y/o el divorcio cualquiera de los cónyuges podrá invocar haber sido él o ella el autor/a de tal separación de hecho, esto es su propia conducta.

Esta situación podría conducir a estimar esta causa como una suerte de abandono de la casa conyugal así como de incumplimiento de los deberes de cohabitación y de asistencia, aspectos que constituyen la esencia de la institución del matrimonio.

En efecto, el requisito previo para la invocación de tal causa como fundamento de la separación de cuerpos y del divorcio ulterior consiste únicamente en la probanza del hecho de "estar al día" en la obligación alimentaria, no en la exigencia de "haber venido cumpliendo" con tal obligación.

Al calificar esta separación de hecho como causa para la separación de cuerpos $y / o$ divorcio las diversas iniciativas legislativas presentadas consideraron únicamente, a efectos de su configuración, el aspecto objetivo esto es, el hecho mismo de la separación- sin analizar el motivo de su origen, situación que pareciera comprobarse de la sola lectura del nuevo inciso $12^{\circ} \mathrm{del}$ artículo $333^{\circ}$ del Código Civil.

Sin embargo, la tercera disposición complementaria y transitoria de la Ley $\mathrm{N}^{\circ} 27495$ dispone que "para efectos de la aplicación del inciso $12^{\circ} \mathrm{del}$ artículo $333^{\circ}$ no se considerará separación de hecho aquella que se produzca por razones laborales, siempre que se acredite el cumplimiento de las obligaciones alimentarias $\mathrm{u}$ otras pactadas por los cónyuges de mutuo acuerdo". 
En su articulo $4^{\circ}$ la misma Ley dispone la incorporación, al Código Civil, de un artículo 345-A cuyo primer párrafo reproduce dicha tercera disposición complementaria y transitoria: "Para invocar el supuesto del inciso $12^{\circ}$ del Artículo $333^{\circ}$ el demandante deberá acreditar que se encuentra al día en el pago de sus obligaciones alimentarias $u$ otras que hayan sido pactadas por los cónyuges decomún acuerdo."

Así queda confirmado que el fundamento consagrado en esta causa no es sólo objetivo.

Interesa mencionar, asimismo, la disposición expresa contenida en el segundo párrafo de este artículo $345-\mathrm{A}^{\circ}$, en virtud de la que -al conocer del proceso incoado por esta causa- el juez "... velará por la estabilidad económica del cónyuge que resulte perjudicado por la separación de hecho...".

Esta norma ratifica el enunciado contenido en la parte final del inciso 12 del artículo $333^{\circ}$ del Código Civil vigente en el sentido en que -al no ser de aplicación en esta causa la disposición del artículo $335^{\circ}$ - la demanda de separación de cuerpos y/o divorcio por la causa de separación de hecho puede fundarse en hecho propio del cónyuge que la interpone: en efecto, tratándose de esta causa, la demanda puede ser interpuesta por cualquiera de los cónyuges.

En el mismo sentido, como quiera que cualquiera de los cónyuges puede resultar perjudicado por la separación de hecho, el juez deberá velar por su estabilidad económica.

Finalmente, la norma del artículo 345-A declara la aplicación "... a favor del cónyuge que resulte más perjudicado por la separación de hecho...", en cuanto sean pertinentes, de los artículos 323, 324, 342, 343, 351 y 352 del Código relativos a los gananciales; a la determinación de la pensión alimenticia; a la pérdida de derechos hereditarios; a la revocación del consentimiento en la separación convencional; a la patria potestad en la separación convencional; a la reparación del cónyuge inocente del divorcio; y a la pérdida de gananciales por el cónyuge divorciado por su culpa.

\section{Conclusión}

No obstante el principio consagrado en la Constitución vigente a la fecha, al haber ampliado las causas que pueden invocarse como sustento de las acciones de separación de cuerpos y divorcio y al haber posibilitado 
expresamente la invocación de los hechos propios como sustento de tales acciones tratándose de la causal contenida en el numeral 12 del artículo $333^{\circ}$ del Código Civil vigente a la fecha y descrita como la separación de hecho de los cónyuges durante un período ininterrumpido de dos años o de cuatro años si los cónyuges tuviesen hijos menores de edad, la normativa civil relativa a la materia facilita la disolución del vínculo del matrimonio, promovido por la comunidad y por el Estado y reconocido por ambos como instituto natural y fundamental de la sociedad.

\section{Referencias}

- Constitución Política del Perú de 1993. (2010) Fondo Editorial Cultura Peruana EIRL. Lima.

- Código Civil del Perú - Decreto Legislativo No 295. (2011) Editorial Gaceta Jurídica, Lima. 
